\title{
Post-surgical treatment of early-stage breast cancer with electronic brachytherapy: an intersociety, multicenter brachytherapy trial
}

This article was published in the following Dove Press journal:

OncoTargets and Therapy

28 October 2010

Number of times this article has been viewed

\author{
Peter D Beitsch' \\ Rakesh R Patel ${ }^{2}$ \\ John D Lorenzetti ${ }^{3}$ \\ James CWurzer ${ }^{4}$ \\ James C Tucker ${ }^{5}$ \\ Susan J Laduzinsky ${ }^{6}$ \\ Morris A Kugler ${ }^{7}$ \\ 'Dallas Surgical Group, Dallas, TX, \\ USA; ${ }^{2}$ Valley Medical Oncology \\ Consultants, Pleasanton, CA, USA; \\ ${ }^{3}$ Breast Specialists, Egg Harbor \\ Township, NJ, USA; ${ }^{4}$ AtlantiCare \\ Regional Medical Center, Egg Harbor \\ Township, NJ, USA; ${ }^{5}$ DCH Regional \\ Medical Center - Tuscaloosa, AL, \\ USA; ' ${ }^{6}$ emorial and St Elizabeth's \\ Cancer Treatment Center, Swansea, \\ IL, USA; ${ }^{7}$ Southern Illinois Surgical \\ Consultants, Maryville, IL, USA
}

Introduction: Electronic brachytherapy (EBT) was developed to allow accelerated partial breast irradiation to be performed in a patient procedure room with minimal shielding. This observational, nonrandomized, multicenter study evaluated EBT as a post-surgical adjuvant radiation therapy for early stage breast cancer.

Methods: This study included women aged 50 years or more with invasive carcinoma or ductal carcinoma in situ, tumor size $\leq 3 \mathrm{~cm}$, negative lymph node status, and negative surgical margins. The endpoints were skin and subcutaneous toxicities, efficacy outcomes, cosmetic outcomes, and device performance. In this interim report, 1-month, 6-month, and 1-year follow-up data are available on 68,59 , and 37 patients, respectively.

Results: The EBT device performed consistently, delivering the prescribed 34 Gy to all 69 patients (10 fractions/patient). Most adverse events were Grade 1 and included firmness, erythema, breast tenderness, hyperpigmentation, pruritis, field contracture, seroma, rash/desquamation, palpable mass, breast edema, hypopigmentation, telangiectasia, and blistering, which were anticipated. Breast infection occurred in two $(2.9 \%)$ patients. No tumor recurrences were reported. Cosmetic outcomes were excellent or good in $83.9 \%-100 \%$ of evaluable patients at 1 month, 6 months, and 1 year.

Conclusion: This observational, nonrandomized, multicenter study demonstrates that this EBT device was reliable and well tolerated as an adjuvant radiation therapy for early stage breast cancer.

Keywords: radiation therapy, electronic brachytherapy, breast cancer

\section{Introduction}

An estimated 254,650 new cases of breast cancer were diagnosed in $2009 .{ }^{1}$ Breast conserving therapy (BCT) for patients with stage I or II breast cancer consists of surgical removal of the tumor with negative margins and axillary sentinel lymph node dissection followed by radiation therapy to further decrease the chance of a recurrence. Several studies have shown BCT to be comparable to mastectomy in terms of overall and disease-free survival for patients. ${ }^{2-7}$ The major advantage of BCT over mastectomy is cosmetic outcome and reduced psychological trauma to the patient. The major disadvantage to $\mathrm{BCT}$ is the prolonged time of radiation treatment. The whole breast radiation portion of $\mathrm{BCT}$ can add 7 weeks to the treatment time, which prevents some women from choosing BCT, particularly if substantial travel time is required to reach the radiation treatment facility. ${ }^{8-10}$

Accelerated partial breast irradiation (APBI) was developed to decrease exposure of healthy tissue to radiation and to decrease the treatment time required for
Correspondence: Peter D Beitsch 7777 Forest Lane, Suite C760, Dallas, TX 75230, USA

Tel + I 9725668039

$\mathrm{Fax}+\mathrm{I} 9725662312$

Email beitsch@aol.com 
breast irradiation from 7 weeks to 1 week. ${ }^{10}$ The method of breast brachytherapy with the longest reported follow-up is multicatheter interstitial brachytherapy. This technique utilizes up to 20 catheters placed through and around the lumpectomy bed to allow delivery of the radiation seed to the target area around the breast cavity. Several studies utilizing this technique have reported favorable cosmesis and rates of local control. ${ }^{11-13}$ However, even using the best imaging available, the technique requires a great deal of experience and skill to position the 20 catheters to cover the required treatment area and is only offered at a few institutions around the country. Other devices have been developed to provide a logistically simpler technique for APBI, and data on local control, toxicity, and cosmesis have been favorable. ${ }^{14-16}$ However, these techniques rely on a ${ }^{192}$ Iridium source, which requires a radiation vault and high-dose-rate (HDR) afterloader unit, which many treatment centers do not have. ${ }^{17}$

An electronic form of brachytherapy (EBT) was developed to allow APBI to be performed in a patient procedure room with minimal shielding. ${ }^{17-19}$ This device (Axxent ${ }^{\circledR}$; Xoft, Inc., Sunnyvale, CA) uses a kilovoltage X-ray source to deliver HDR radiation to the tumor bed through a balloon applicator (Figure 1). One-year follow-up data from a multicenter study demonstrated control rates, cosmesis, and tolerability similar to other forms of breast brachytherapy. ${ }^{20}$ This form of brachytherapy has been shown in dosimetric studies to deliver lower doses of radiation to the heart and lung compared with ${ }^{192}$ Iridium-based balloon brachytherapy. ${ }^{17,21}$ In addition, electronic source anisotropy and multiple dwell positions obtainable with this device may allow a decreased skin dose while maintaining optimal target coverage. ${ }^{22}$ A kilovoltage brachytherapy approach has the potential to allow APBI to be more accessible to breast cancer patients who do not live in close proximity to a radiation treatment facility with an HDR afterloader unit. This observational, nonrandomized, multicenter, data collection study was

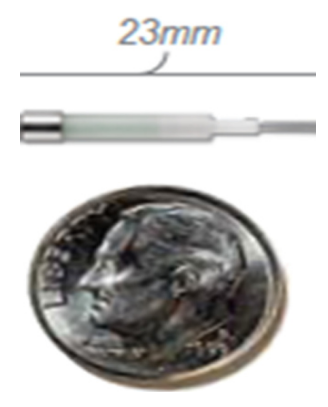

Figure I Electronic source. designed to prospectively evaluate the safety and efficacy of EBT as a post-surgical adjuvant radiation therapy for early stage breast cancer.

\section{Methods}

The study protocol was developed under the guidance of the American Brachytherapy Society (ABS), the American Society of Breast Surgeons (ASBS), and the American College of Radiation Oncology (ACRO). Representatives from these three organizations formed an oversight committee, which was responsible for finalization of the protocol and case report forms as well as oversight of the study management. An independent data safety monitoring board comprised of representatives from the $\mathrm{ABS}, \mathrm{ASBS}$, and $\mathrm{ACRO}$ reviewed and adjudicated the safety data at least quarterly.

The protocol and informed consent form were approved by an institutional review board for each site that participated in the study. Patients signed an informed consent form prior to study entry. The study was conducted in accordance with the Declaration of Helsinki and all applicable regulations. The study sponsor (Xoft, Inc.) selected the investigators, study centers, and monitors, provided study training to investigators and study staff, and reviewed study implementation regularly to ensure protocol and regulatory compliance as well as adherence to good clinical practices. The clinical study sites provided all contact with health care services for patients and entered the data on electronic case report forms in an electronic data capture (EDC) system. The EDC standards are compliant with the United States Food and Drug Administration (FDA) federal regulations for electronic records and electronic signatures, which utilizes unique user names, passwords, and audit trails for data entry and edits. The study monitors performed source data verification and ensured protocol compliance. An independent biostatistician performed the data analyses.

\section{Patients}

Patients had to be 50 years of age or older, be estrogen-receptor positive, have a tumor size $\leq 3 \mathrm{~cm}$, have a tumor histology consistent with invasive carcinoma or ductal carcinoma in situ, be sentinel lymph node negative with negative surgical margins (National Surgical Adjuvant Breast and Bowel Project definition, no tumor on ink) after final surgery, and have a life expectancy $>5$ years. Patients were excluded if they were pregnant or breastfeeding, were not using birth control, had collagen vascular disease (including scleroderma, systemic sclerosis, or active lupus), had infiltrating lobular histology, or had prior ipsilateral radiation to the thorax or breast. 
A post-lumpectomy ultrasound (US) or computed tomography (CT) was used to properly assess each patient's eligibility for balloon applicator placement. CT was the ultimate determinant for assessing adequate skin spacing following balloon applicator insertion.

\section{Materials}

The FDA-cleared EBT system consists of the kilovoltage $\mathrm{X}$-ray source, the mobile controller, and the balloon applicators. The balloon applicator is used to position tissue and an electronic source during breast brachytherapy treatments. The applicator consists of a multilumen catheter with an inflatable balloon assembly at its distal end. The applicators are available in an ellipsoidal shape or in three sizes of a spherical shape, all with variable diameters. The Model 110 controller provides the user interface, monitors safety-related parameters, provides an interface for the external equipment, and delivers power to the X-ray source. The X-ray source pullback device on the controller is used to physically translate the source to specific dwell positions during radiation treatment. The source delivers HDR, low-energy radiation by generating 50 kilovolt $\mathrm{X}$-rays without the use of radioactive isotopes. The source has a radiation profile that is characterized according to the American Association of Physicists in Medicine TG-43 format..$^{23}$ Air kerma strength for the source was measured using an integrated well ionization chamber prior to the delivery of each fraction of radiation.

\section{Device placement}

Following standard lumpectomy surgery and confirmation of pathology results, an EBT balloon applicator was selected to best fit the tumor cavity. The balloon applicator was placed following a closed cavity placement technique only. The use of cavity expander/space-occupying devices was permitted as determined to be appropriate by the physician. The balloon applicator was inflated with saline to fill the cavity at the time of placement and remained inflated throughout the 5-day treatment period.

\section{Treatment}

A total of 34 Gy was prescribed to $10 \mathrm{~mm}$ distance radially from the surface of the balloon. Two fractions per day, each $3.4 \mathrm{~Gy}$, separated by at least 6 hours were to be administered over 5 treatment days for a total of 34 Gy. Balloon placement, conformance, and skin distance were assessed prior to each fraction using US, fluoroscopy, or CT for a total of 10 assessments. In particular, the balloon applicator was verified to be symmetrical with the central source lumen within
$2 \mathrm{~mm}$ of the central axis of the balloon. All nonconforming volumes such as trapped air and/or seroma had to be $\leq 10 \%$ of the planning target volume for evaluation (PTV_EVAL). The applicator was removed using standard sterile techniques after the completion of the final EBT fraction.

A US image was required at each follow-up visit in accordance with the local standard of care. A mammogram was required based on standard practice after $\mathrm{BCT}$ and to assist in the diagnosis of subcutaneous toxicities. Patient follow-up visits were scheduled to occur at 1 month, 6 months, 1 year, 2 years, 3 years, 4 years, and 5 years post-treatment.

\section{Treatment planning}

A CT was required for three-dimensional (3D) treatment planning following balloon applicator placement. Treatment planning was performed on commercially available radiation treatment planning systems such as Varian BrachyVision ${ }^{\mathrm{TM}}$ or Nucletron PLATO. CT data acquisition with $3.0 \mathrm{~mm}$ slices or less was required. Source location, number of positions, and dwell times were at the discretion of the physician and were determined by CT-based 3D treatment planning to produce the optimal conformal plan in accordance with volume definition and dose requirements. The treatment plan used for each patient was based on analysis of the volumetric dose including dose-volume histogram analyses of the PTV_EVAL and critical normal tissues. The treatment target was the breast tissue immediately surrounding the balloon to a measured distance of $10 \mathrm{~mm}$ from the balloon surface. The PTV_EVAL was delineated as the breast tissue volume bounded by the uniform expansion of the balloon radius in all dimensions by $10 \mathrm{~mm}$ minus the balloon volume.

\section{Primary endpoints}

The incidence of signs and symptoms of skin toxicities and subcutaneous toxicities were recorded at the follow-up visits. Specific toxicities that can result from radiation therapy and any other adverse events were recorded at the follow-up visits. The Common Terminology Criteria for Adverse Events version 3 were used. ${ }^{24}$

Cosmetic outcome was recorded at the follow-up visits and was graded based on the Harvard Cosmesis Scale by a health care professional. ${ }^{25}$ This four-point scale includes ratings of excellent (treated breast looks essentially the same as the opposite breast), good (minimal but identifiable effects of radiation procedure on the treated breast), fair (significant effects of radiation procedure on the treated breast), and poor (severe normal tissue sequelae secondary to irradiation procedure). 


\section{Secondary endpoints}

Device performance during balloon applicator placement and the course of the radiation treatments was evaluated in terms of the ability to deliver treatment and performance of the system and applicator. Local-regional breast cancer recurrence and survival (overall and disease free) were also recorded at each follow-up visit.

\section{Statistical analyses}

Descriptive statistics were reported as the number (n), mean, minimum, and maximum for continuous variables. For nominal variables, the $\mathrm{n}$ and proportion for each category were reported. A Wilcoxon two-sample $t$-test was used to evaluate the association of cosmesis and balloon volume or balloonsurface-to-skin distance. A chi-square was used to evaluate the association of cosmesis and the rate of adverse events.

\section{Results}

The study included 69 female patients as summarized in Table 1. Tumor characteristics at the time of surgery are summarized in Table 2. Most patients (75.4\%) did not have a family history of breast cancer. This interim analysis reports the duration of follow-up for the patients through May 31, 2010. Of the 69 enrolled and treated, 68 have been evaluated at 1 month, 59 patients at 6 months, and 37 patients at 1 year of follow-up. In addition to the 69 patients who were treated, eight patients underwent balloon insertion and did not proceed to radiation therapy due to inadequate distance from the balloon surface to the skin in six patients or inadequate distance from the rib in two patients. One additional patient who consented to the treatment experienced a myocardial infarction (MI) and did not proceed with balloon insertion due to the MI.

The applicator was placed post-lumpectomy by a surgeon in $66(95.7 \%)$ patients and by a radiation oncologist in two (2.9\%) patients; the applicator was placed at the time of

Table I Patient characteristics at baseline

\begin{tabular}{ll}
\hline Number of patients & 69 \\
Mean age in years (range) & $67.5(43.4-85.3)$ \\
Female & $69(100 \%)$ \\
Menopausal status & \\
Post-menopausal & $64(92.7 \%)$ \\
Peri-menopausal & $2(2.9 \%)$ \\
Pre-menopausal & $3(4.4 \%)$ \\
Race & \\
Caucasian & $54(78.3 \%)$ \\
African-American & $13(18.8 \%)$ \\
Hispanic & $1(1.5 \%)$ \\
Asian & $1(1.5 \%)$ \\
\hline
\end{tabular}

Table 2 Tumor characteristics at baseline

\begin{tabular}{ll}
\hline Tumor size (mean and range) & $1.2(0.1-3.0) \mathrm{cm}$ \\
$\mathrm{N}=65^{\mathrm{a}}$ & \\
Initial volume of excised tissue & $161.6(7.20-690.00) \mathrm{mL}$ \\
(mean and range) & \\
Tumor characteristics in all patients & $69(100 \%)$ \\
AJCC class & $20(29.0 \%)$ \\
Tis & $8(11.6 \%)$ \\
TIa & $18(26.1 \%)$ \\
TIb & $20(29.0 \%)$ \\
TIc & $3(4.4 \%)$ \\
T2 & $19(27.5 \%)$ \\
Histopathologic grade & $21(30.4 \%)$ \\
Grade I well differentiated & $12(17.4 \%)$ \\
Grade 2 moderately differentiated & $17(24.6 \%)$ \\
Grade 3 poorly differentiated & \\
Grade not available & $42(60.9 \%)$ \\
Lesion location (side) & $27(39.1 \%)$ \\
Left side & \\
Right side & $44(63.8 \%)$ \\
Lesion location (vertical) & $8(11.6 \%)$ \\
Upper & $17(24.6 \%)$ \\
Lower & $38(55.1 \%)$ \\
Midline & $15(21.7 \%)$ \\
Lesion location (horizontal) & $16(23.2 \%)$ \\
Outer &
\end{tabular}

Note: ${ }^{2}$ Tumor size not recorded in the medical chart of four DCIS patients. Abbreviation: AJCC, American Joint Committee on Cancer.

lumpectomy in the operating room by both the surgeon and the radiation oncologist in one patient $(1.4 \%)$. The procedure took place in a procedure room in $65(94.2 \%)$ patients and in an operating room or elsewhere in four (5.8\%) patients. Sedation was provided for $22(31.9 \%)$ patients, and local anesthesia was administered to $67(97.1 \%)$ patients. The procedure lasted a mean duration of 24.3 minutes and ranged from 4.0 to 69.0 minutes. In most cases a trocar was used (95.6\%) with a lateral approach (84.1\%). Surgical clips were present in $33.3 \%$ of cases. Most patients (95.7\%) underwent US assessment of the distance from the balloon surface to the skin surface at the time of applicator placement, and the mean distance was $12.8 \mathrm{~mm}$ (range 7.0-22.0 mm). One patient was not assessed, and two patients, who underwent CT scans at the time of applicator placement, had mean distances of $6.8 \mathrm{~mm}$ and $18.0 \mathrm{~mm}$. The mean volume of fluid used to inflate the balloon applicators was $56.8 \mathrm{~mL}$ and ranged from 30.0 to $140.0 \mathrm{~mL}$. Spherical balloon applicators of size 3-4 cm, 4-5 cm, and 5-6 cm were used in 17 (24.6\%), $39(56.5 \%)$, and $12(17.4 \%)$ patients, respectively. The $5 \times 7 \mathrm{~cm}$ ellipsoidal balloon applicator was used in one (1.5\%) patient (Table 3). Three balloon deflations occurred at the time of placement due to contact with a sharp object; 
Table 3 Applicator sizes used and respective saline volumes

Applicator sizes used and saline instilled (0.9NS) in $\mathrm{mL}$

Final applicator model

\begin{tabular}{lllll}
\hline $\begin{array}{l}\text { Balloon } \\
\text { applicator } \\
\text { diameters }\end{array}$ & $\begin{array}{l}\mathbf{3 - 4} \mathbf{~ c m} \\
\text { spherical }\end{array}$ & $\begin{array}{l}\mathbf{4 - 5} \mathbf{~ c m} \\
\text { spherical }\end{array}$ & $\begin{array}{l}\mathbf{5 - 6} \mathbf{~ c m} \\
\text { spherical }\end{array}$ & $\begin{array}{l}\mathbf{5 \times 7} \mathbf{~ c m} \\
\text { ellipsoidal }\end{array}$ \\
\hline $\mathrm{N}$ & 17 & 39 & 12 & $\mathrm{I}$ \\
Mean $(\mathrm{mL})$ & 36.47 & 53.41 & 89.58 & 140.00 \\
Std Dev $(\mathrm{mL})$ & 6.06 & 9.38 & 21.37 & - \\
Min $(\mathrm{mL})$ & 30.00 & 30.00 & 60.00 & 140.00 \\
Max $(\mathrm{mL})$ & 45.00 & 75.00 & 130.00 & 140.00 \\
\hline
\end{tabular}

Abbreviations: NS, normal saline; Std Dev, standard deviation; Min, minimum Max, maximum.

the balloon applicators were replaced, and treatment was completed. One patient reported breast tenderness at the time of placement; no other adverse events were reported at the placement visit.

The prescribed radiation dose was $34 \mathrm{~Gy}$, to be delivered in 10 fractions over 5 days in all 69 patients. The prescribed fractional radiation dose of 3.4 Gy was successfully delivered in 688 of 690 fractions (99.7\%) with $3.3 \mathrm{~Gy}$ and $3.5 \mathrm{~Gy}$ delivered in 2 of 690 fractions $(0.3 \%)$. All patients received $34 \mathrm{~Gy}$ over 10 fractions. The skin bridge was evaluated by CT prior to treatment; the mean minimum balloon-to-skin surface distance was $15.5 \mathrm{~mm}$ and ranged from 5.5 to $42.0 \mathrm{~mm}$. The mean planning treatment volume was $110.2 \mathrm{~mL}$ and ranged from 35.0 to $192.0 \mathrm{~mL}$. Erythema was reported in three patients during a treatment visit; no other adverse events were reported at treatment visits. A technical difficulty arose with the X-ray sources during 17 of $690(2.5 \%)$ fractions. This was due to a source arc, which occurs when the vacuum chamber at the tip of the treatment catheter has a very small electrical discharge resulting in a voltage reduction from 50 kilovolts to ground. This occurs inside the grounded tube and does not affect the patient. The device controller has an automatic detection function, which prompts the operator to replace the source, which results in a 5-10 minute delay. In each case, the source was replaced, and treatment was completed. Controller issues, which related to the pullback mechanism or coolant flow in the applicator, arose during 3 of $690(0.4 \%)$ fractions; these issues were addressed, and treatments were completed. After each patient completed 10 fractional treatments, the balloon applicator was removed, typically in a procedure room (68.5\%).

Adverse events were collected at each follow-up visit. Most treatment-related adverse events were Grade 1, manageable, and typical of radiation therapy (Table 4). There were 29 Grade 2 adverse events in 15 patients, and 19 of the 29 (65.5\%) events occurred at one month (Table 5). Two patients
Table 4 Grade I adverse events. Adverse events that were possibly, probably, or definitely related to applicator placement or radiation therapy as reported at each follow-up visit unless otherwise noted

\begin{tabular}{|c|c|c|c|}
\hline Grade I events & I month & 6 months & I year \\
\hline Number of patients & $68^{\mathrm{a}}$ & 59 & 37 \\
\hline Induration/firmness-slight & $25(36.8 \%)^{b}$ & $14(23.7 \%)$ & $5(13.5 \%)$ \\
\hline Erythema & $27(39.7 \%)^{c}$ & I (I.7\%) & I (2.7\%) \\
\hline Breast tenderness & I $4(20.6 \%)^{d}$ & II (I8.6\%) & $4(10.8 \%)$ \\
\hline Hyperpigmentation & $14(20.6 \%)$ & $6(10.2 \%)$ & $2(5.4 \%)$ \\
\hline Pruritis & 14 (20.6\%) & $2(3.4 \%)$ & I (2.7\%) \\
\hline Field contracture-slight & $7(10.3 \%)$ & $6(10.2 \%)^{e}$ & $2(5.4 \%)$ \\
\hline \multicolumn{4}{|l|}{ indent in skin } \\
\hline Seroma & $8(11.8 \%)$ & $4(6.8 \%)$ & $4(10.8 \%)$ \\
\hline Rash/desquamation-dry & $9(13.2 \%)$ & 0 & 0 \\
\hline Palpable mass & $3(4.4 \%)^{e}$ & $2(3.4 \%)$ & $4(10.8 \%)$ \\
\hline Rash/desquamation-moist & $6(8.8 \%)$ & 0 & 0 \\
\hline Breast edema & $3(4.4 \%)$ & I (I.7\%) & I (2.7\%) \\
\hline Infection & 0 & I (I.7\%) & 0 \\
\hline $\begin{array}{l}\text { Loss of subcutaneous } \\
\text { tissue on palpation }\end{array}$ & I (I.5\%) & I (I.7\%) & I (2.7\%) \\
\hline Atrophy-slight & $2(2.9 \%)$ & 0 & I (2.7\%) \\
\hline Hypopigmentation & $\mathrm{I}(\mathrm{I} .5 \%)$ & $2(3.4 \%)$ & I (2.7\%) \\
\hline Telangiectasia & $2(2.9 \%)$ & I (I.7\%) & 0 \\
\hline Lymphedema & 0 & $2(3.4 \%)$ & 0 \\
\hline Pigmentation change & $(1.5 \%)$ & 0 & 0 \\
\hline Bleeding at treated site & I (I.5\%) & 0 & 0 \\
\hline Blistering & I (I.5\%) & 0 & 0 \\
\hline Skin thickening & 0 & I (I.7\%) & 0 \\
\hline $\begin{array}{l}\text { Wound dehiscence } \\
\text { (wound complication - } \\
\text { noninfection) }\end{array}$ & I (I.4\%) & 0 & 0 \\
\hline
\end{tabular}

Notes: ane of the 69 treated patients did not complete the I-month follow-up visit due to an acute myocardial infarction and subsequent death; no treatment-related adverse events occurred in this patient; ' lncludes one unscheduled visit around I month post-treatment; Includes three treatment visits and one unscheduled visit around I month; 'Includes two unscheduled visits around I month post-treatment and one Balloon Applicator Insertion visit; elncludes one occurrence in the nontreated breast; ' Includes one with an indurated scar.

reported one or more adverse events that were assessed as Grade 3 by the physician (Table 5). One patient had diarrhea related to Clostridium difficile infection resulting from prophylactic antibiotic use and a significant field contracture both at 1 month post treatment. The other patient had a fibrosis of connective tissue at 1 year post-treatment that the investigator deemed to be possibly related to treatment. No recurrences were reported, and there were no deaths due to cancer. One patient experienced an acute myocardial infarction when 1-month follow-up was due and later expired.

Cosmetic results were evaluated by the investigator as excellent, good, fair, or poor at each visit based on the Harvard Scale. ${ }^{25}$ Cosmesis was excellent or good (minimal or no identifiable effects of radiation) in $83.9 \%, 84.5 \%$, and $100 \%$ of evaluable patients at 1 month, 6 months, and 1 year. An analysis of cosmetic results revealed an association between 
Table 5 Grade 2 and 3 adverse events. Adverse events that were possibly, probably, or definitely related to applicator placement or radiation therapy as reported at each follow-up visit

\begin{tabular}{llll}
\hline & I month & 6 months & I year \\
\hline Grade 2 events & & & \\
Number of patients & $68^{\mathrm{a}}$ & 59 & 37 \\
Induration/firmness & $4(5.9 \%)$ & $3(5.1 \%)$ & $\mathrm{I}(2.7 \%)$ \\
Erythema & $4(5.9 \%)$ & 0 & $\mathrm{I}(2.7)^{\mathrm{d}}$ \\
Seroma & $\mathrm{I}(\mathrm{I} .5 \%)$ & $2(3.4 \%)^{\mathrm{c}}$ & $\mathrm{I}(2.7 \%)$ \\
Rash/desquamation - moist & $3(4.4 \%)^{\mathrm{b}}$ & 0 & 0 \\
Breast tenderness & $\mathrm{I}(\mathrm{I} .5 \%)$ & $\mathrm{I}(\mathrm{I} .7 \%)$ & 0 \\
Hypopigmentation & $2(2.9 \%)$ & 0 & 0 \\
Palpable mass & $2(2.9 \%)$ & 0 & 0 \\
Field contracture - slight & 0 & 0 & $\mathrm{I}(2.7 \%)$ \\
indent in skin & & & \\
Field contracture - significant & 0 & $\mathrm{I}(\mathrm{I} .7 \%)$ & 0 \\
Infection & $\mathrm{I}(\mathrm{I} .5 \%)$ & 0 & 0 \\
Grade 3 events & & & \\
Field contracture - significant & $\mathrm{I}(\mathrm{I} .5 \%)$ & 0 & 0 \\
Fibrosis connective tissue & 0 & 0 & $\mathrm{I}(2.7 \%)^{\mathrm{c}}$ \\
\hline
\end{tabular}

Notes: ane of the 69 treated patients did not complete the I-month follow-up visit due to an acute myocardial infarction and subsequent death; no treatmentrelated adverse events occurred in this patient; 'Includes three unscheduled visits around I month post-treatment; Includes one unscheduled visit around 6 months post-treatment; 'Includes one unscheduled visit around I year post-treatment; ${ }^{\circ}$ One patient had Grade 3 diarrhea that was related to a Clostridium difficile infection due to a prophylactic antibiotic.

fair or poor cosmesis and an increased rate of visible adverse events (erythema, rash, field contracture, pigmentation changes, and other visible effects) at 6 months $(P=0.04)$ but not at 1 month. Further analysis showed that the 6-month cosmetic results were not associated with balloon volume or the distance from the balloon surface to the skin prior to treatment.

\section{Discussion}

This observational, nonrandomized, multicenter study was undertaken following FDA clearance of the EBT device in order to better understand the clinical use of EBT as an adjuvant radiation therapy for early stage breast cancer. Representatives from the ABS, the ASBS, and the ACRO guided protocol development, study conduct, and data analyses. The prospectively defined primary endpoints were device performance, skin and subcutaneous toxicities, efficacy outcomes, and cosmetic outcome. The present report includes 68 patients who have received treatment and have completed at least 1 month of follow-up. Six-month and 1-year follow-up data are available on 59 and 37 patients respectively.

The EBT device performed consistently, delivering the prescribed 34 Gy to all patients. In two fractions, 3.3 and 3.5 Gy were delivered to one patient who received a total of 34 Gy by the end of all 10 fractions. No technical issues occurred during placement or removal of the balloon applicator other than the deflation of three balloons related to contact with sharp objects; the three balloons were replaced. Technical issues with the X-ray source or controller during treatment were infrequent ( $<3 \%$ of treatment visits) and were easily addressed.

Adverse events were collected during each patient visit. Reported adverse events were consistent with data from other studies of breast brachytherapy, although the rate of breast infection was very low (2.9\%) in this EBT study. Studies with other forms of breast brachytherapy have reported infection rates of 4\%-16\%. ${ }^{26-30}$ Erythema, pruritis, and desquamation typically resolved by the 6-month or 1-year follow-up visit, whereas the occurrence of breast tenderness, firmness, and seroma declined gradually. There have been no tumor recurrences reported as of the 6-month follow-up visit in 59 patients and the 1-year follow-up visit in 37 patients.

Cosmetic outcomes were excellent or good in $83.9 \%-100 \%$ of evaluable patients at 1 month, 6 months, and 1 year. These outcomes are similar to those reported with other forms of breast brachytherapy. These cosmetic results are favorable compared with an earlier EBT study in which 44 patients were treated with EBT for early stage breast cancer. ${ }^{20}$ In the earlier study, cosmetic results were excellent or good in $75 \%$ of patients at the 1-year follow-up visit. Cosmetic results may be adversely affected by narrow skin bridges. In this study, the mean distance from balloon surface to skin surface was $12.8 \mathrm{~mm}$ and ranged from 7.0 to $22.0 \mathrm{~mm}$; in the previous study, the mean distance was nearly double $(25.1 \mathrm{~mm})$ and ranged from 8.0 to $96.0 \mathrm{~mm}$, which does not explain the differences in cosmesis. This study showed an association between the rate of visible adverse events and cosmetic results; since this study appears to have a somewhat lower rate of Grade 2-3 adverse events as compared with the earlier study, the disparity in cosmetic results may be related to the specific adverse events reported in each study. The experience with EBT gained during the earlier trial informed the study design, training materials, and device instructions for this study and other EBT studies. In addition, the present trial utilized the next generation controller (Model 110), which may have provided some advantages over the controller (Model 100) utilized in the earlier study.

The risks associated with use of EBT include complications associated with the surgical implantation of the balloon applicator. Complications arising from the delivery of EBT appear to be similar to those resulting from other forms of breast irradiation, although dosimetric analyses from other studies demonstrate a reduced radiation dose to the heart and lung with EBT as compared with the same dose of breast 
radiation from a radioisotope source. ${ }^{17,21}$ Dickler et al compared dosimetric data from patients treated with ${ }^{192}$ Iridiumbased balloon brachytherapy (IrBT) with data from EBT treatment plans for the same patients. The mean ipsilateral lung dose (\%V30) was 3.7\% with IrBT as compared with $1.1 \%$ with EBT $(P<0.05)$; the mean heart dose $(\% \mathrm{~V} 5)$ was $59.2 \%$ with IrBT as compared with $9.4 \%$ with EBT $(P<0.05) .{ }^{17}$ Dosimetry was also reported by Mehta et al, in which patients treated with EBT had a mean ipsilateral lung dose $(\% \mathrm{~V} 30)$ of $1.17( \pm 1.15)$ and a mean heart dose $\left(\%\right.$ V5) of $20.15( \pm 18.48) .{ }^{20}$ Mille et al reported a dosimetric comparison of IrBT and EBT in a virtual patient with leftside breast cancer and found that EBT resulted in a lower dose to healthy organ tissue (excluding ribs) than IrBT by a median dose reduction factor of $28 .^{21}$ The clinical effects of a reduced dose to healthy tissue have not been fully evaluated. The radiation dose and dose rate prescribed during this study were within the standard brachytherapy doses used in breast irradiation.

The potential benefits of EBT may include improved tumor control over surgery alone, shortened treatment time over whole breast irradiation, a reduction in the amount of radiation delivered to normal tissue as compared with whole breast irradiation and isotope-based balloon brachytherapy, and greater access to brachytherapy treatment facilities compared with isotope-based irradiation technologies, which require a specifically shielded radiation vault and HDR afterloader unit. These study results are limited by the length of follow up, and longer follow-up data are needed.

\section{Conclusion}

One-year follow-up data from this observational, nonrandomized, multicenter study demonstrate that this EBT device was reliable and well tolerated as an adjuvant radiation therapy for early stage breast cancer. Adverse events were consistent with those reported with radioisotope-based APBI.

\section{Acknowledgments}

The authors thank the patients who participated in this study and their families. The authors wish to thank the research staff for their help with this study. The authors acknowledge the contributions of the Oversight Committee members: Douglas Arthur, MD, of ABS; Peter Beitsch, MD, of ASBS; Jeffrey Demanes, MD, of ACRO; Arve Gillette, MD, of ACRO, Michael Kinney, MD, of ASBS; Henry Kuerer, MD, of ASBS; Helen Pass, MD, of ASBS; Rakesh Patel, MD, of ABS; Frank Vicini, MD, of ABS; David Wazer, MD, of ABS and ACRO; James Welsh, MD, of ACRO; and Pat Whitworth, MD, of
ASBS. The authors acknowledge the contributions of the Data Safety Monitoring Board: Sushil Beriwal, MD, of ABS; Tricia Kelly, MD, of ASBS; and William Rate, MD, of ACRO. The authors acknowledge the numerous investigators who contributed to this study: George W Nunn, Dwelvin L Simmons, Michael S Gilligan, Tappan Roy, Jonathon K Foley, John P Thropay, Timothy D Nichols, Bruce A Bornstein, Elizabeth P Tito, Steven C Lane, Julie G White, Manjeet Chadha, and Susan K Boolbol.

\section{Disclosure}

The authors report no conflicts of interest in this work.

\section{References}

1. Cancer Facts and Figures on www.cancer.org [Web site] American Cancer Society; c2010 [updated 2010]. Available from http:// www.cancer.org/. Accessed 2010 Jun 5.

2. Veronesi U, Banei A, Del Vecchio M, et al. Comparison of Halsted mastectomy with quadrantectomy, axillary dissection, and radiotherapy in early breast cancer: long-term results. Eur J Cancer Clin Oncol. 1986;9:1085-1089.

3. Blichert-Toft M, Brincker M, Andersen JA, et al. A Danish randomized trial comparing breast preserving therapy with a mastectomy in mammary carcinoma. Anta Oncol. 1988;27:671-677.

4. van Dongen JA, Bartelink H, Fentiman IS, et al. Randomized clinical trial to assess the value of breast-conserving therapy in stage I and II breast cancer. EORTC 10801 trial. JNCI Monogr. 1992;11:15-18.

5. Sarrazin D, Le MG, Arriagada R, et al. Ten-year results of a randomized trial comparing a conservative treatment to a mastectomy in early breast cancer. Radiother Oncol. 1989;14:177-184.

6. Fisher B, Redmond C, Poisson R, et al. Eight year results of a randomized clinical trial comparing total mastectomy and lumpectomy with or without radiation in the treatment of breast cancer. $N$ Eng J Med. 1989;320:822-828.

7. Lichter AS, Lippman ME, Danforth DN, et al. Mastectomy versus breast-conserving therapy in the treatment of stage I and II carcinoma of the breast: a randomized trial at the national Cancer Institute. $J$ Clin Oncol. 1992;10:976-983.

8. Athas WF, Adams-Cameron M, Hunt WC, et al. Travel distance to radiation therapy and receipt of radiotherapy following breast conserving surgery. J Natl Cancer Inst. 2000;92:269-271.

9. Schroen AT, Brenin DR, Kelly MD. Impact of patient distance to radiation therapy on mastectomy use in early-stage breast cancer patients. J Clin Oncol. 2005;23:7074-7080.

10. Pawlik TM, Buchholz TA, Kuerer HM. The biologic rational for and emerging role of accelerated partial breast irradiation for breast cancer. J Am Coll Surg. 2004;199:479-492.

11. Vicini FA, Antonucci JV, Wallace M, et al. Long-term efficacy and patterns of failure after accelerated partial breast irradiation: a molecular assay-based clonality evaluation. Int J Radiat Oncol Biol Phys. 2007;68:341-346.

12. King TA, Bolton JS, Kuske RR, et al. Long-term results of widefield brachytherapy as the sole method of radiation therapy after segmental mastectomy for $\mathrm{T}($ is, 1,2$)$ breast cancer. Am J Surg. 2000;180:299-304.

13. Polgar C, Major T, Fodor J, et al. High-dose-rate brachytherapy alone versus whole breast radiotherapy with or without tumor bed boost after breast-conserving surgery: seven-year results of a comparative study. Int J Radiat Oncol Biol Phys. 2004;60:1173-1181.

14. Israel PZ, Vicini F, Robbins AB, et al. Ductal carcinoma in situ of the breast treated with accelerated partial breast irradiation using balloonbased brachytherapy. Ann Surg Oncol. Epub 2010 May 5. 
15. Yashar CM, Blair S, Wallace A, Scanderbeg D. Initial clinical experience with the Strut-Adjusted Volume Implant brachytherapy applicator for accelerated partial breast irradiation. Brachytherapy. 2009;8:367-372.

16. Vicini F, Beitsch P, Quiet C, et al. Five-year analysis of treatment efficacy and cosmesis by the American Society of Breast Surgeons Mammosite Breast Brachytherapy Registry Trial in patients treated with accelerated partial breast irradiation. Int J Radiat Oncol Biol Phys. Epub 2010 May 14.

17. Dickler A, Kirk MC, Seif N, et al. A dosimetric comparison of Xoft Electronic Brachytherapy high-dose-rate brachytherapy and Xoft Axxent electronic brachytherapy. Brachytherapy. 2007;6:164-168.

18. Dickler A. Xoft Axxent electronic brachytherapy: a new device for deliverying brachytherapy to the breast. Nat Clin Pract Oncol. 2009;6:138-142.

19. Park CC, Yom SS, Podgorsak MB, et al. American Society for Therapeutic Radiology and Oncology (ASTRO) Emerging Technology Committee report on electronic brachytherapy. Int J Radiat Oncol Biol Phys. 2010;76:963-972.

20. Mehta VK, Algan O, Griem KL, et al. Experience with an electronic brachytherapy technique for intracavitary accelerated partial breast irradiation. Am J Clin Oncol. 2010; 33(4):327-335.

21. Mille MM, Xu XG, Rivard JM. Comparison of organ doses for patients undergoing balloon brachytherapy of the breast with HDR 192Ir or electronic sources using monte carlo simulations in a heterogeneous human phantom. Med Phys. 2010;37(2):662-671.

22. Hepel JT, Hiatt JR, Cardarelli GA, Wazer DE. Modeling study for optimization of skin dose for partial breast irradiation using Xoft Axxent electronic brachytherapy applicator. Brachytherapy. 2010;9:81-85.
23. Rivard MJ, Davis SD, DeWerd LA, et al. Calculated and measured brachytherapy dosimetry parameters in water for the Xoft Axxent X-Ray Source: an electronic brachytherapy source. Med Phys. 2006;33(11):4020-4032.

24. Trotti A, Colevas AD, Setser A, et al. CTCAE V3.0: development of a comprehensive grading system for the adverse effects of cancer treatment. Semin Radiat Oncol. 2003;13:176-181.

25. Rose MA, Olivotto I, Cady B, et al. Conservative surgery and radiation therapy for early breast cancer. Long-term cosmetic results. Arch Surg. 1989;124:153-157.

26. Keisch M, Vicini F, Kuske RR, et al. Initial clinical experience with the MammoSite Breast Brachytherapy Applicator in women with early stage breast cancer treated with breast conserving therapy. Int J Radiat Oncol Biol Phys. 2003;55(2):289-293.

27. Haley M, Beriwal S, Heron DE, et al. MammoSite accelerated partial breast irradiation: a single institution outcomes analysis with two-year follow-up. Brachytherapy. 2009;8:9-13.

28. Chao KK, Vicini FA, Wallace M, et al. Analysis of treatment efficacy, cosmesis, and toxicity using the Mammosite breast brachytherapy catheter to deliver accelerated partial-breast irradiation: the William Beaumont Hospital Experience. Int J Radiat Oncol Biol Phys. 2007;69(1):32-40.

29. Richards GM, Berson AM, Resigno J, et al. Acute toxicity of high dose rate brachytherapy with the MammoSite applicator in patients with early stage breast cancer. Ann of Surg Onc. 2004;11(8):739-746.

30. Harper JL, Jenrette JM, Vanek KN, et al. Acute complications of MammoSite brachytherapy: a single institutions initial clinical experience. Int J Radiat Oncol Biol Phys. 2005;61(1):169-174.
OncoTargets and Therapy

\section{Publish your work in this journal}

OncoTargets and Therapy is an international, peer-reviewed, open access journal focusing on the pathological basis of all cancers, potential targets for therapy and treatment protocols employed to improve the management of cancer patients. The journal also focuses on the impact of management programs and new therapeutic agents and protocols on

\section{Dovepress}

patient perspectives such as quality of life, adherence and satisfaction The manuscript management system is completely online and includes a very quick and fair peer-review system, which is all easy to use. Visit http://www.dovepress.com/testimonials.php to read real quotes from published authors. 